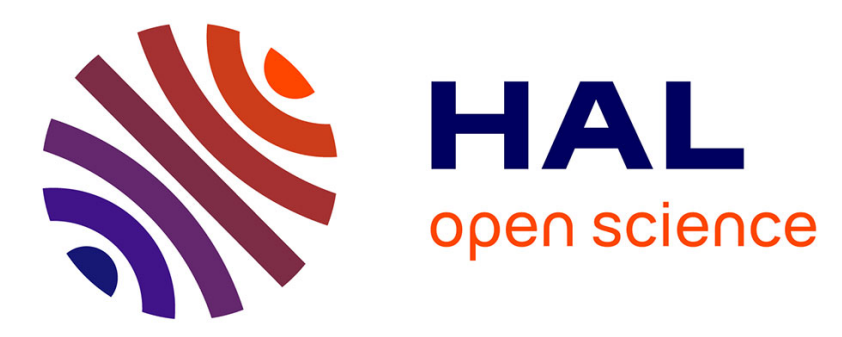

\title{
An Efficient Numerical Technique to Predict Phase Responses of Reconfigurable Reflectarray Cells with Mutual Coupling
}

Clement Yann, Renaud Loison, Raphaël Gillard, Michèle Labeyrie, Jean-Paul Martinaud

\section{To cite this version:}

Clement Yann, Renaud Loison, Raphaël Gillard, Michèle Labeyrie, Jean-Paul Martinaud. An Efficient Numerical Technique to Predict Phase Responses of Reconfigurable Reflectarray Cells with Mutual Coupling. IEEE MTT-S International Microwave Symposium, Jun 2012, Montréal, Canada. pp. 1-3. hal-00768647

\section{HAL Id: hal-00768647 https://hal.science/hal-00768647}

Submitted on 22 Dec 2012

HAL is a multi-disciplinary open access archive for the deposit and dissemination of scientific research documents, whether they are published or not. The documents may come from teaching and research institutions in France or abroad, or from public or private research centers.
L'archive ouverte pluridisciplinaire HAL, est destinée au dépôt et à la diffusion de documents scientifiques de niveau recherche, publiés ou non, émanant des établissements d'enseignement et de recherche français ou étrangers, des laboratoires publics ou privés. 


\title{
An Efficient Numerical Technique to Predict Phase Responses of Reconfigurable Reflectarray Cells with Mutual Coupling
}

\author{
Clément Yann*\#, Renaud Loison*, Raphaël Gillard*, Michèle Labeyrie\#, Jean-Paul Martinaud\#. \\ *European University of Brittany, France, INSA, IETR, UMR 6164, F-35708 Rennes \\ \#THALES Systèmes Aéroportés, Elancourt, France
}

\begin{abstract}
This paper presents a numerical technique to predict realistic phase responses of active cells within a reflectarray. The phase respon ses of an active cell are determined as a function of the states of the neighboring cells. The phase probability distributions are computed and realistic phase responses are then evaluated. A synthesis application is presented in order to highlight the in terest of the realistic phase responses.
\end{abstract}

Index Terms - Antennas, reflectarray, numerical simulation, mutual coupling, array synthesis.

\section{INTRODUCTION}

Reflectarrays [1]-[2] are attractive antennas due to their low profile, and their possibilities for beam shaping and electronic beam control. A reflectarray consists of an array of radiating cells which is illuminated by a primary feed. Each cell introduces an appropriate phase-shift to the incident wave to steer the main beam in a desired direction. For passive reflectarrays, the reflection phase of each cell is adjusted by modifying the cell's geometry. For reconfigurable reflectarrays (RRA), electronic beam scanning is achieved by inserting active loads, such as PIN diodes [3] or MEMS [4], inside each phase-shifter cell. The active cells are geometrically identical but differ from the state of the active elements.

The synthesis of RRA is a challenging optimization problem. To synthesize the array, the states of the active cells are selected so as to comply with the desired phase-shifts and to produce the required antenna radiation pattern. The selection of the active cells is commonly performed by considering the phase responses calculated with Floquet boundary conditions [5]. The Floquet approach assumes that the unitary cell is surrounded by identical cells, which is not verified in an actual RRA. The mutual coupling effects are not accurately taken into account and this approximation leads to prediction errors on the radiation pattern.

In this paper, we propose a numerical technique to determine more realistic phase responses of surrounded active cells than the Floquet ones. The proposed technique relies on a statistical approach and consists in evaluating the phase response distribution of the active cell when its environment varies. We show that this technique gives relevant information in order to synthesize RRA.

The paper is organized as follows: Section II A discusses the previous work dedicated to the analysis of RRA. Next,
Section II B presents the proposed technique to determine the phase response distribution when varying the cell's neighbors. Section III describes a synthesis application of this technique. Concluding remarks are given in Section IV.

\section{PRINCIPLE OF THE PROPOSED METHOD}

\section{A. Analysis method}

The method, presented in [6], consists in studying each active cell surrounded by its actual neighbors. For convenience, a sub-array composed of the studied cell and its two closest neighbors is considered (Fig. 1) but the method is naturally expandable to a larger sub-array. For the sake of simplicity, the considered radiating cell includes only one active element.

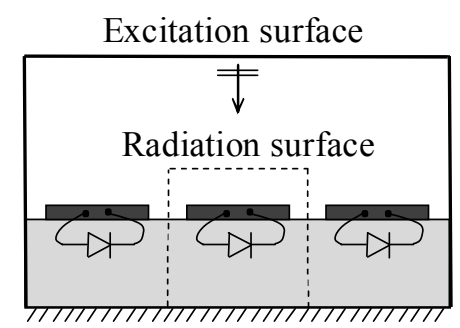

Fig. 1. Structure to analyze.

An incident plane wave is applied to the whole sub-array and the reflected field from the studied cell is computed. The mutual coupling effects are realistically accounted for since the accurate environment is considered. Using Huygens principle, the reflected field can be derived from equivalent sources on the radiation surface in the scattered field region. The specific state of active elements within the studied cell and its neighbors is taken into account through lightweight circuit simulations.

The method can determine promptly and accurately the response of a cell considering the actual environment. This advantage is used in this paper to analyze the effect of the environment on the phase response of the cell.

\section{A. Proposed technique to determine the most realistic phase response of surrounded cells}

The study of one state of the active cell is now described in details. A sub-array composed of the studied cell and its 
closest neighbors is considered. The active elements of the central cell are turned into a specific state while the states of the neighboring cells vary. Then, the phase response of the central cell is determined as a function of the states of the neighboring cells for all possible combinations of the active elements. The phase response of the cell corresponds to the phase of the co-polarization component of the electric field in the specular direction. Finally, thanks to this exhaustive analysis, the probability distribution of the phase response is determined. It is thus possible to identify the mean phase response $\mu$ and the standard deviation $\sigma$ of the distribution. We show in next section that, when synthesizing a RRA, it is preferable to use the mean phase responses than the Floquet ones.

\section{APPLICATION}

The technique presented above is applied to active cells developed by THALES Systèmes Aéroportés [7]. A reflectarray demonstrator has been designed and optimal performance in radiation has been demonstrated in X-band.

\section{A. Description of the cell}

The unit-cell consists of a printed circuit with 4 diodes inside an opened rectangular metallic cavity as shown in Fig. 2.

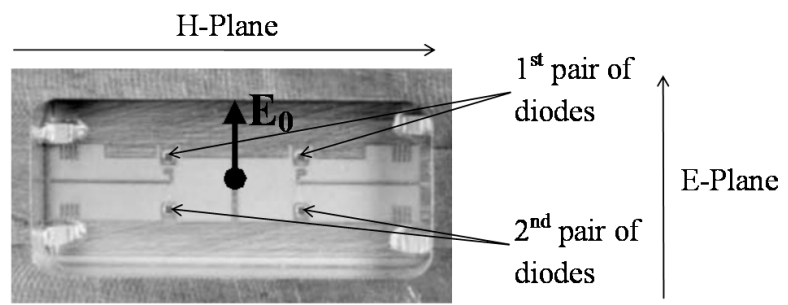

Fig. 2. RRA phase shifting cell.

The four diodes are paired which leads to four possible states (Table I). Diodes have a forward resistance $\left(Z_{\text {On }}\right)$ of 2.5 Ohms while their reverse blocking capacitance $\left(\mathrm{Z}_{\mathrm{Off}}\right)$ is $50 \mathrm{fF}$. An approximately $360^{\circ}$ phase range is covered by the four different states with about $90^{\circ}$ progressive steps between each state.

\section{B. Probability distribution of the phase response}

Four probability distributions, corresponding to the four states of the cell, are computed. They show the probability of a phase response as a function of the configurations of surrounding cells.

To do so, a $3 \times 3$ sub-array composed by the unit-cell and the direct neighbors is considered. All the configurations of the active elements inside the sub-array are analyzed. For a $3 \times 3$ sub-array with 2-bit reconfigurable cells, there are $2^{8 \times 2}$ different configurations for each state of the central cell.

In this section, only the "Off-On" state is analyzed in details given that the most important deviation is observed between the mean phase response and the Floquet one. The central cell of the $3 \times 3$ sub-array is fixed in the "Off-On" state and the phase response is computed for all the surrounding cells configurations. The probability distribution of the phase response is reported in Fig. 3. The mean phase response $\mu$ and the standard deviation $\sigma$ are computed. As highlighted in the probability distribution, the phase obtained with the Floquet approach is $-175.8^{\circ}$. However, the probability to obtain this phase is only 0.04 . If all the configurations of the $3 \times 3$ subarray are considered, the mean phase response is $-149.6^{\circ}$. As a consequence, a difference of $26.2^{\circ}$ occurred in most of the configurations. Moreover, the standard deviation of the phase probability distribution is $18.9^{\circ}$. In this distribution, $70 \%$ of the configurations fall within one standard deviation of the mean phase response, that is to say, in the range $\left[(\mu-\sigma)=-168.5^{\circ} ; \quad(\mu+\sigma)=-130.7^{\circ}\right]$. As a consequence, the phase responses are spread out over a large range of values which can lead to approximation errors in the synthesis process.

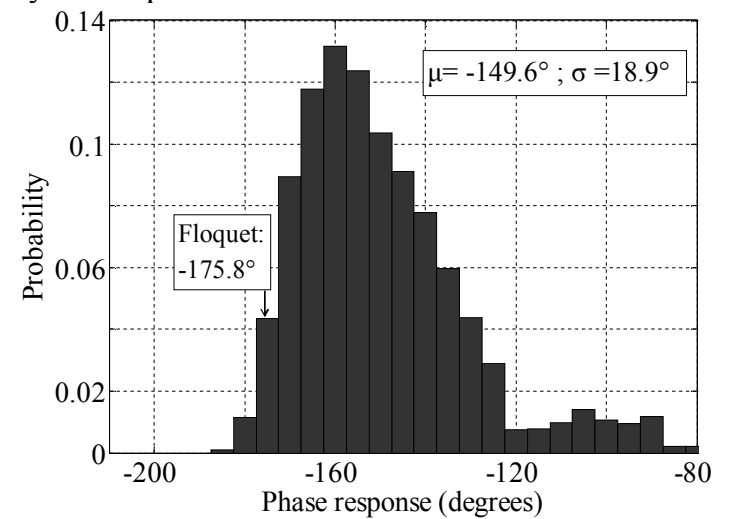

Fig. 3. Phase probability distribution of the "Off-On" state

The results obtained with the other states are reported in Table I. The differences between the mean phase responses and the Floquet ones are in the same range and the probability distributions have the same trend. It confirms that the environment has an effect on the phase response of the unitcell.

TABLE I

PhASE RESPONSES OF THE CELL AT $8.7 \mathrm{GHz}$

\begin{tabular}{|l|l|l|l|}
\hline \multirow{2}{*}{ Phase } & \multirow{2}{*}{ Floquet } & \multicolumn{2}{|c|}{$\begin{array}{l}\text { Proposed technique } \\
\text { response } \mu\end{array}$} \\
\hline On-On & $30.9^{\circ}$ & $\begin{array}{l}\text { Standard } \\
\text { deviation } \sigma\end{array}$ \\
\hline Off-Off & $-49.1^{\circ}$ & $-52.9^{\circ}$ & $10,6^{\circ}$ \\
\hline On-Off & $-123.7^{\circ}$ & $-104.3^{\circ}$ & $15,0^{\circ}$ \\
\hline Off-On & $-175.8^{\circ}$ & $-149.6^{\circ}$ & $17,0^{\circ}$ \\
\hline
\end{tabular}

Concerning the computation time of the proposed technique, all the configurations of the active elements can be analyzed with only one light-weight electromagnetic simulation and fast circuit simulations. With an Intel ${ }^{\circledR}$ Xeon ${ }^{\circledR}$ E5506 2.13GHz Quad Core and 48 GB RAM, the complete analysis requires 72 minutes for the electromagnetic 
simulation and 243 minutes for the post-processing which analyzes $2^{18}$ configurations.

In conclusion, the neighboring cells can have a significant impact on the behavior of a studied cell. With the Floquet approach, the current environment of each cell is not taken into account which introduces an error on the phase response. This approximation can have an effect on the synthesis of the array.

In the next section, we demonstrate the relevance of mean phase responses for the synthesis of a RRA.

\section{B. Array synthesis}

A $10 \times 10$ array is considered for comparing different simulation approaches. The considered test case (Fig. 5) is designed to provide a pencil beam in the $\left(\varphi_{\max }=45^{\circ} ; \theta_{\max }=\right.$ $30^{\circ}$ ) direction when illuminated by an incident plane wave.

\begin{tabular}{|l|l|l|l|l|l|l|l|}
\hline $\mathbf{Z}$ & $\mathbf{X}$ \\
\hline
\end{tabular}

Fig. 5. Phase-only synthesis of a 10x10 array with the main beam in the $\left(\varphi_{\max }=45^{\circ} ; \theta_{\max }=30^{\circ}\right)$ direction.

A HFSS ${ }^{\circledR}$ full-wave electromagnetic simulation of the $10 \times 10$ array is carried out. This simulation of the overall array is the reference simulation and allows to compare results from different approaches. First, the radiation pattern of the overall $10 \times 10$ array is computed using the Floquet phase of each active cell. This pattern is obtained by multiplying the array factor computed with the Floquet phases and the unit-cell radiation pattern, which is determined by simulating a simplified model of the unit-cell. Then, the radiation pattern of the overall 10x10 array is computed using the mean phase response of each active cell. It is given by the product of the array factor computed with the mean phase responses and the unit-cell radiation pattern. The radiation patterns are compared to the reference simulation to assess which phase law leads to the better predicted radiation pattern.

The radiation patterns obtained with the three approaches are reported in Fig. 6. A noticeable difference of $7.2 \mathrm{~dB}$ exists for the first quantification lobe between the radiation pattern from Floquet phases and the reference. In comparison, there is a difference of $0.9 \mathrm{~dB}$ between the radiation pattern from mean phase responses and the reference. For the second quantification lobe, the differences are less significant but the radiation pattern from mean phase responses is more accurate than the one with the Floquet phases. The radiation pattern with mean phase responses has better predictive accuracy of the quantification lobes. As a consequence, the array synthesis from the mean phase responses is a better alternative to the synthesis from Floquet phases.

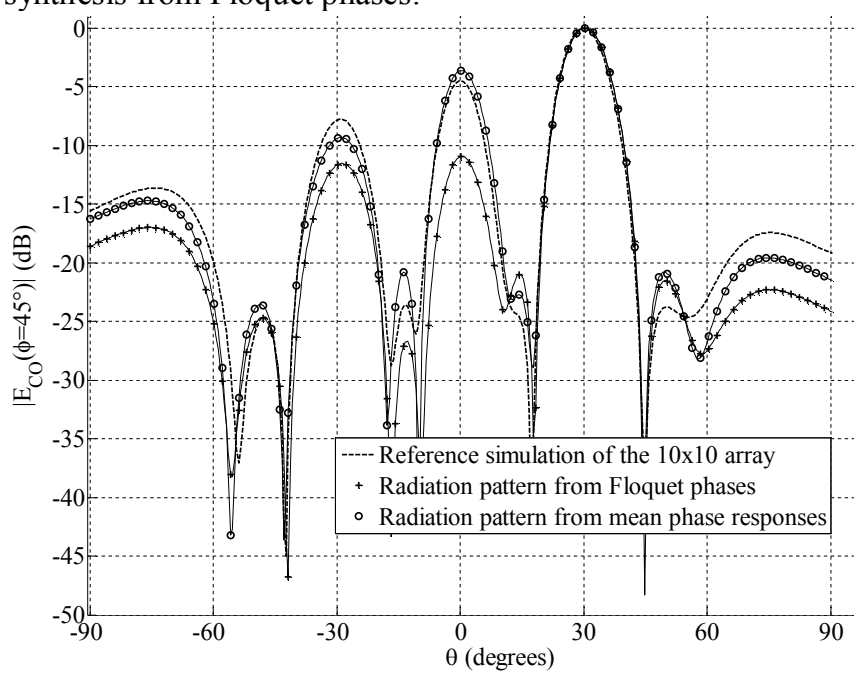

Fig. 6. Analysis of a 10x10 array.

\section{CONCLUSION}

In this paper, an innovative technique to determine the phase response of an active cell incorporated in a non-uniform environment has been presented. It has shown that it is essential to take into account the accurate environment of the active cell. For the array synthesis, mean phase responses have been defined from the phase probability distributions. Then, they are used for the synthesis to provide a better predictive radiation pattern than the Floquet ones.

\section{REFERENCES}

[1] J. Huang, and J. Encinar, Reflectarray Antennas. Wiley-IEEE Press, 2007.

[2] W. Menzel, Jiang Li, and S. Dieter, "Folded reflectarray antenna based on a single layer reflector with increased phase angle range," in European Conference on Antennas and Propagation, Berlin, Germany, 2009.

[3] R. Pereira, R. Gillard, R. Sauleau, P. Potier, T. Dousset and X. Delestre, "Four-state dual polarisation unit-cells for reflectarray applications", Electronics letters, volume 46, n²11, May 2010.

[4] J. Perruisseau-Carrier, and A. K. Skrivervik, "Monolithic MEMS-based reflectarray cell digitally reconfigurable over a $360^{\circ}$ phase range," in IEEE Antennas and Wireless Propagation Letters, vol. 7, pp. 138-141, 2008.

[5] J. Montgomery, "Scattering by an infinite periodic array of microstrip elements," IEEE Trans. on Antennas and Propagation, vol. 26, no. 6, pp. 850-854, Nov. 1978.

[6] C. Yann, R. Loison, R. Gillard, M. Labeyrie, and J.-P. Martinaud, "Global technique analysis for reconfigurable reflectarray antennas," in European Conference on Antennas and Propagation, Rome, Italy, 2011.

[7] X. Delestre, T. Dousset, M. Labeyrie, and C. Renard, "New Challenges for Active ReflectArrays," in International Radar Conference, Bordeaux, France, 2009. 